\title{
Research on Digital Transformation Strategy of Distribution Network Construction Management in "New Era"
}

\author{
Xiaobing Teng ${ }^{1}$ Yuguang Zheng ${ }^{2}$ Zhenfeng $\operatorname{Li}^{1}$ Zhen Liu' ${ }^{1}$ Qiang $\operatorname{Jin}^{2}$ Hongjun $\mathrm{Li}^{2}$ \\ ${ }^{1}$ Zhejiang Huayun Electric Power Engineering Design Consulting Co., Ltd., Hangzhou, Zhejiang 310000, China \\ ${ }^{2}$ State Grid Economic and Technology Research Institute Co., Ltd., Beijing 102209, China \\ *Corresponding author. Email: zhengyuguang@chinasperi.sgcc.com.cn
}

\begin{abstract}
The construction management of distribution network is the key to the high quality development and construction of power grid. In order to support the company's strategic goal of building "an international leading Energy Internet Enterprise with Chinese characteristics", this paper clarifies the existing problems in the construction based on the historical background, and puts forward targeted measures for the transformation of construction management from traditional to digital methods.
\end{abstract}

Keywords: distribution network engineering, construction management, digitalization, new era.

\section{INTRODUCTION}

As the development of Chinese Socialism enters a new stage, the regional economic layouts of strengthening high-quality development, coordinating urban and rural development, and accelerating the modernization of agriculture and rural areas is deepening day by day. Based on the reality and modern background, this paper analyzes the current situation faced by the construction management of distribution energy network. At the same time, in-depth summary of the power grid company distribution network construction management status, construction enterprises, operation mode and other aspects of the situation. Combining the characteristics of the distribution network project with numerous points, long lines and wide area, it is necessary to sort out the outstanding problems existing in the current distribution network project construction management and propose countermeasures ${ }^{[1 \sim 3]}$. In this way, we will build a digital management system for the construction of distribution network projects, promote the improvement of the construction management level of distribution network projects, lay a good foundation for the realization of a reasonable, safe, reliable, and cost-effective distribution network management structure, and contribute to the "14th Five-Year Plan" distribution network construction.

\section{NEW ERA POWER GRID CALLS FOR EFFICIENT ENGINEERING CONSTRUCTION MANAGEMENT SYSTEM}

The demand for high-quality development. The Fifth Plenary Session of the 19th Central Committee of the Party pointed out that the development of socialism with Chinese characteristics has entered a new stage. To implement the new development concept and build a new development pattern, it is required to complement the shortcomings of the developing power grid, eliminate potential safety hazards, improve the distribution network power supply capacity, actively serve regional balanced development, and effectively meet people's electricity demand for a better life.

The need for safety and reliability. The "Fourteenth Five-Year Plan for National Economic and Social Development and the Outline of Long-Term Goals for 2035" systematically incorporates power security into national security strategy, which is important for State Grid to ensure the stability of energy supply and the quality of engineering construction. Management has put forward higher requirements, and it is necessary to strengthen safety production control ability and management level. 
The need to improve quality and efficiency. The high-quality development of the power grid requires improvement of construction level, reduction of costs, and exploration of potentials. The key is to make efforts to extend the power supply capacity and safety level of the distribution network continuously, ensure the construction quality, technical adaptability and economic rationality. To achieve a comprehensive and comprehensive "international leading" level of distribution network management, we should allocate resources such as technology, manpower and capital reasonably, and make every effort to realize the coordinated development of distribution network safety, quality and efficiency.

The requirement of controlling construction cost. Stated in the "Government Work Report":" Every expenditure must be carefully calculated and spent on important stuff. To develop with high-quality, we must establish the idea of living a tight life." With the reformation of the power system, we are required to insist on precise investment, conduct scientific and reasonable analysis of the economics of project construction, and eliminate waste.

\section{THE CURRENT DISTRIBUTION NETWORK PROJECT CONSTRUCTION MANAGEMENT SYSTEM NEEDS TO BE IMPROVED}

The existing distribution network project management system needs to adapt to the demands of the changing management situation. Currently:

Distribution network construction management presents "Fewer people and More programs". For State Grid, most province, city, and county companies have very limited specific position for the distribution network construction management. A huge part of local electric companies use temporary employees to manage distribution network construction progress, which may lead weak sense of belonging, poor business continuity, insufficient management penetration, and progressive management effectiveness.

Management and control methods need to be strengthened. Presently, there are breakpoints when using data of the STATE GRID in the project management and control, and the systems cannot be connected. In this way, the value of the data is very restricted, which affects the system unity. Multiple systems and duplication of functions cause repeated entry of original data, which leads low efficiency and dissatisfaction at work. Insufficient data analysis functions limits distribution network management efficiency improvement ${ }^{[4]}$.

Digital transformation should be implemented in distribute network construction management. Project coordinate matters spent too much manpower. It's difficult to match project application and investment, which involves many departments. And the project approval mechanism is not flexible, which is difficult to adapt to the construction requirements of the smart power grid ${ }^{[5]}$. The traditional manage process restricts the project's compliance management and the effective implementation of requirements. The complex procedures and unclear responsibilities when adjusting projects call for digital transformation in distribute network management.

\section{THE STRATEGIC OUTLOOK OF TRANSFORMING AN EFFICIENT DISTRIBUTED NETWORK ENGINEERING MANAGEMENT SYSTEM}

\subsection{Improve the Management System and Enhance the Organization's Support Capabilities}

Carry out top-level design is the key. From project initiation to project closure, the first item is carrying out the revision and improvement of the institution covering the entire process which includes safety, quality, and progress plan, to enhance the feasibility and vitality of the system. Promote special approval of emergency projects should be also considered ${ }^{[6]}$. Secondly, build immediately after approval can avoid the phenomenon of "snatching seats", which smooths the channel for project changes and adjustments. Classify the cost of power distribution projects as non-competitive invest, could stimulate the enthusiasm of participating companies to enhance project safety and quality ${ }^{[7]}$ Moreover, the material reserve node should closely follow the investment release node, and the fund release node closely follows the material reserve node.

\subsection{Build Information Sharing Platform, Strict Construction Enterprise Qualification Review}

It's important to realize national linkage of information ${ }^{[8]}$ : 1. Implement the various regulations on enterprise qualification management, and strictly review the necessary qualifications required by construction enterprises such as the license for installation (repair, test) power facilities, and the safety production license for construction enterprises; 2. Make full use of shared information, enrich big data application scenarios, build evaluation systems and models, and develop data profiling for construction units and construction personnel. 3. Increase the proportion of inspections of construction sites, check the management of equipment and personnel, Identify the number of effective employees of the construction unit, and make the "Leather Bag Companies" have nowhere to hide; 4. Optimize the bidding strategy, increase the entry threshold of registered capital, bearing capacity and 
historical performance make requirements, and make high-quality construction companies to permeate distribute network construction increasingly deeper; 5 . Combining with local reality, take county as the unit, select outstanding companies, limit the number of construction units, refine the comprehensive scoring mechanism of construction enterprises, file and keep irregularities.

\subsection{Improve the Performance Evaluation System and Effectively Carry out Incentives and Punishment}

The application of evaluation mechanism is to empower construction management. The focus is to clarify the performance evaluation scope, evaluation process, evaluation content, index system and evaluation model of the distribution network project, and strengthen the leading role of the manage department and the supervision department in performance evaluation. ${ }^{[7]}$ The core is to apply the performance evaluation results to the construction service procurement link and create an evaluation system by applying cloud chain technology: 1. Collect multi-disciplinary data such as safety supervision, operation and maintenance, reduce subjective factors, simplify operation process, and evaluation results can be automatically generated; 2 . Summarize evaluation data and realize one-click sharing, establish "red and black lists", rewards and punishments are confessed and implemented to individuals; 3. Introduce competition, let the "good companies" do more projects, bring up long-term cooperation teams, and urge construction companies to take the initiative to standardize and strengthen management.

\subsection{Strengthen the Data Center and Realize Business Integration}

To achieve the goal of improving the lean management level of distribution network engineering construction, it's necessary to set the principles as improving management efficiency, reducing the burden on the basic offices, and sharing information widely. As the result of building data center, we can explore deep into the needs of different management levels, optimize and solidify construction processes, standardize related systems such as planning, ERP, budgetary estimates, etc., to help achieve accurate project implementation, project management real-time statistics, automatic analysis, intelligent early warning, comprehensive team management coverage, objective evaluation ${ }^{[9]}$.

\subsection{Relying on the Management System, Solidly Impel the "Four Controls"}

1. Pay attention to construction plan management: Considering the power outage plan, material arrangement, and the construction company's bearing capacity, it's necessary to reasonably arrange the construction period, strictly review the construction plan, and avoid "double skin" between the plan and site. 2. Focus on bringing up the construction team: To strengthen construction teams, we should clarify the staffing requirements of construction teams, and ensure that the safety equipment and supervisor are always in place; On the other hand, by strictly implement the subcontract filing procedures and confirming the labour contract relations, we can prevent unqualified teams from engaging in project construction. 3. Increase the control of construction site personnel. guarantee the qualifications level is to prevent workers with poor safety awareness, sick safety records, and insufficient technical capabilities from entering the site. By implementing the real-name system with "QR code" for identity information, we can achieve " Prior recording, entering with a permit and process managing ". When all kinds of information is quantified, the number of violations will be cut down dramatically. 4. Improve on-site safety measures. Strengthen on-site safety is to strengthen the control of personnel, system, implementation, and supervision. One of the approaches is to promote the video monitoring system, online monitoring can be used to ensure the key procedures. And the use of advanced technologies such as face recognition and cloud network video can increase the control level of key nodes, and improve the efficiency of security management ${ }^{[10]}$.

\section{CONCLUSION}

As the development of socialism with Chinese characteristics has entered a new era, the transformation of electrical energy system and increasingly extended distributed network recalls for a developed distribute network management system with extreme high efficiency and reliability. And the system should have the function of budget control.

Distributed power network projects hold the characteristics of the numerous points, long lines and wide area. Recently, the scale of distribution network projects grow rapidly, while the specific position for the distribution network construction management is very limited. On the other hand, there are breakpoints when using data in management process, and digital systems are not connected which devalues the use of data and affects the system unity. In this way, digital transformation should be implemented.

In order to achieve the four goals in the "Guiding Opinions on Accelerating the Construction and 
Transformation of Distribution Networks" (stable economic growth, structural adjustment of distribution and transmission networks, speeding up the conversion to green power and serving communities), we need to revision management System institution, build and promote a comprehensive digital Sharing Platform, improve the use of Supplier Performance Evaluation, and Realize Business Integration.

\section{ACKNOWLEDGMENTS}

The title "ACKNOWLEDGMENTS" should be in all caps and should be placed above the references. The references should be consistent within the article and follow the same style. List all the references with full details.

\section{REFERENCES}

[1] Xu Chenjing. Research and Application of Lean Planning for Distribution Network [D]. Hangzhou: Zhejiang University, 2014.

[2] Xu Bingyin, Li Tianyou, Xue Yongduan. Intelligent distribution network and distribution automation $[\mathrm{J}]$. Automation of Electric Power Systems, 2009, 33(17): 38-41.

[3] Han Junlin. Discussion on safety management of distribution network construction site [J]. Shaanxi Electric Power, 2009, 11.

[4] Wang Guanqing. 10kV power distribution network engineering construction technology management measures $[\mathrm{J}]$. Engineering Technology Research, 2020, 5(23): 184-185.

[5] Chen Weiqiang, Shen Bo, Zhou Gang. Research on improvement measures for construction safety management of $10 \mathrm{kV}$ distribution network engineering $[\mathrm{J}]$. Henan Science and Technology, 2020, 39(32): 85-87.

[6] Tang Jinshui. Technical management of $10 \mathrm{kV}$ power distribution network construction $[\mathrm{J}]$. Value Engineering, 2020, 39(21): 16-17.

[7] Ren Dongbo. Safety risk management measures in the construction of distribution network projects[J]. Science and Technology Innovation, 2019, 4(25): 161-162.

[8] Xiong Fengling. Analysis of construction technology management strategy for power distribution network engineering $[\mathrm{J}]$. Science and Technology Wind, 2014, 4(19): 150.

[9] Liang Huiquan. Power distribution network engineering construction technology management strategy[J]. China High-tech Enterprise, 2014, 4 (18): 75-76.
[10] Lu Qiwen, Liang Yuqi, Fan Jianwen. The hidden dangers and countermeasures of safety management during the construction of $10 \mathrm{kV}$ distribution network project[J]. Electronic World, 2012, 4(24): 68 . 